\title{
Evaluasi Kebijakan Kebandarudaraan Pada Bandar Udara Tempuling Di Kabupaten Indragiri Hilir
}

\author{
1'Yesi Nazila, ${ }^{2}$ Febri Yuliani, ${ }^{3}$ Hasim As'ari \\ ${ }^{123}$ Program Studi Magister Ilmu Administrasi, Universitas Riau, Indonesia
}

e-mail: yesinazila@gmail.com

\begin{abstract}
Abstrak
Pengelolaan bandara tidak hanya dilaksanakan oleh kota-kota besar, namun juga oleh kota-kota pada tingkat Kabupaten yang ada diseluruh Indonesia termasuk Kabupaten Indragiri Hilir. Kota Tembilahan Kabupaten Indragiri Hilir merupakan Kabupaten yang juga dikenal sebagai kota seribu jembatan dengan luas $11,606 \mathrm{~km}^{2}$ yang sebagian daerahnya adalah rawa-rawa. Bandar Udara Tempuling merupakan hasil dari kebijakan yang dikeluarkan guna untuk memenuhi misi pembangunan diharapkan akan menjadi Kabupaten yang maju dan berkembang dari segala bidang termasuk dalam hal pembangunan fisik dan peningkatan kesejahteraan masyarakatnya, dengan tolak ukur pendapatan, masyarakat yang meningkat, distribusi pendapatan yang merata, dan dengan melihat potensi yang dimiliki oleh Kabuapeten Indragiri Hilir dari berbagai bidang perkebunan, pertanian, kelautan, dan perindustrian. Untuk pengelolaan bandar udara tersebut maka dibutuhkanlah sebuah evaluasi dalam proses untuk menilai dari awal bagaimana kebijakan tersebut dapat terlakasana dengan baik sehingga sasaran yang telah di wacanakan dapat terarah dengan benar.

Evaluasi Kebijakan Kebandarudaraan Pada Bandar Udara Tempuling Di Kabupaten Indragiri Hilir menggunakan teori tipe evaluasi dengan skema penilaian menurut Nurcholis yaitu ada 4 tipe : (1) input, (2) proses, (3) output, (4) outcomes. Adapun faktor penghambat dari penyelenggaraan bandar udara tempuling ialah keterbatasan sumber daya manusia (SDM) baik dalam segi kualitas maupun kuantitas dalam perencanaan hingga dalam pelaksanaannya, selain itu keterbatasan kewenangan Pemerintah daerah Kabupaten Indragiri Hilir dalam menangani kegiatan bandar udara. Tidak berkesinambuanganya pemerintah daerah dalam melihat aspek jangka panjang terhadap bandar udara, Serta kurangnya sosialisasi dari pemerintah kepada masyarakat mengenai bandar udara tempuling.
\end{abstract}

Keywords: kebijakan, evaluasi, input, proses, output, outcomes

\section{Abstract}

City management is not just implemented by big cities, but the city at the district level throughout indonesia, including the regency of indragiri hilir. The city of tembilahan indragiri hilir is a regency that is known as the city series bridge with an area 11,606 KM ${ }^{2}$ the most of the area is swamps. Airport in tempuling is the result of the policies issued in order to fulfill the mission of development expected will be a district that developed anda developing of all fields in terms of physical development anda improvement of the welfare of the community, with a measure of income, increase of people, equitable distribution, and to see the potential which is owned by the regency of indragiri hilir from a variety of field crops, agriculture, marine, and industrial. To management airport is then it takes a evaluation in the process of to assess from the begining of how the policy can happen well so that the target of that had been on the formulation of can disreced by right.

Airport policy evaluation at the tempuling airport in the regency of indragiri downstream using the theory of evaluation with a Nurcholis assesment scheme namely there are 4 types : (1) input, (2) process, (3) output, (4) outcomes. As for the inhibiting factors of the operation of the tempuling airpory are the 
limitation of human resources both in terms of quality and quantity in planning and implementation, in addition to the limited aoythority of the downstream indragiri distrirt goverment in seeing the long term aspects of the tempuling airport, as well as the lack of socialization from the goverment to the public regardiong the aerodrome airport.

Kata Kunci : Policy, Evaluation, Input, Process, Output, Outcomes

\section{PENDAHULUAN}

Indonesia adalah salah satu Negara berkembang yang memiliki 34 Provinsi dan wilayah kepulauan terbesar di dunia terdiri dari 17.504 pulau, oleh karena itu dengan daerah perairan terbesar. Indonesia memerlukan sebuah alat transportasi yang dapat digunakan untuk membantu daerah-daerah yang tidak terjangkau untuk mendapatkan kesejahteraan juga pemerataan dalam pembangunan, dengan transportasi yang digunakan sebagai sarana penunjang. Tanpa adanya sarana transportasi yang memadai maka akan sulit untuk menghubungkan seluruh daerah di kepulauan, kebutuhan akan transportasi merupakan tulang punggung perekonomian nasional, regional, dan lokal baik diperkotaan maupun dipedasaan. Transportasi yang ada di laut, darat, maupun udara memegang peran vital dalam faktor sosial ekonomi melalui fungsi distribusi antar daerah satu dengan daerah yang lain.

Pemerintah Daerah akhir-akhir ini dalam pelaksanaannya untuk memenuhi tuntutan dan keinginan pembangunan transportasi baik darat, laut dan udara di berbagai wilayah, dalam melakukan studi kelayakan belum mempertimbangkan secara akurat ketersediaan sumberdaya dan potensi yang telah ada. Pembangunan transportasi juga belum sepenuhnya mengacu kepada ketentuan peraturan dan ketentuan teknis pembangunan transportasi. Pada tahun 2019 pemerintah memfokuskan untuk pembangunan transportasi udara agar dapat memperlancar ekonomi dan masuknya investasi asing ke daerah-daerah, dengan demikian daerah-daerah tersebut dapat berkembang dan bermafaat, sehingga pemerintah daerah membangun sebuah bandar udara agar transportasi dapat menjadi satu hal yang membangun daerah untuk berkembang dan di optimalkan guna kelancaran dan pemanfaatan bagi daerah yang akan dibangun bandr udara

Kabupaten Indragiri Hilir merupakan kabupaten yang memiliki jumlah penduduk sebanyak 629.841 jiwa dan memiliki luas wilayah $11.605,87 \mathrm{~km}^{2}$ yang wilayahnya berbatasan dengan:

$>$ Sebelah Utara : Kabupaten Pelalawan

$>$ Sebelah Selatan $\quad$ : Kabupaten Tanjung Jabung Provinsi Jambi

$>$ Sebelah Barat $\quad$ : Kabupaten Indragiri Hulu

$>$ Sebelah Timar : Provinsi Kepulauan Riau

Fisiograpi daerah Kabupataen Indragiri Hilir sebagian besar dari luas wilayah atau 93,31\% daerah Kabupaten Indragiri Hilir merupakan daerah dataran rendah, yaitu daerah endapan sungai, daerah rawa dengan tanah gambut, daerah hutan payau (mangrove) dan terdiri atas pulau-pulau besar dan kecil dengan luas lebih kurang 1.082.953,06 hektar dengan rata-rata ketinggian lebih kurang 0-3 Meter dari permukaan laut. Sedangkan sebagian kecilnya $6.69 \%$ berupa daerah berbukit-bukit dengan ketinggian rata-rata 6-35 meter dari permukaan laut yang terdapat dibagian Selatan Sungai Reteh Kecamatan Keritang, yang berbatasan dengan Provinsi Jambi. Dengan ketinggian tesbut, maka pad aumumnya daerah ini dipengaruhi oleh pasang surut, apalagi bila diperhatikan fisiografisnya dimana tnah-tanah tesebut terbelah-belah oleh beberapa sungai, sehingga membentuk gugusan pulau-pulau.

Pembangunan bandara ini merupakan salah satu upaya pemerintah daerah Inhil dalam pengembangan Kota Tembilahan yang saat ini semakin sempit, sehingga diperlukan pengembangan Kota kesegala penjuru, untuk itu keberadaan bandara tempuling digeser kepinggir kota dengan harapan 
komponen lainnya bisa mengikuti. Agar adanya pemerataan pembangunan untuk semua kawasan di Kabupaten Inhil yang saat ini pembangunan hanya berfokus dalam kawasan di Kabupeten Kota saja, diharapkan dengan kebijakan pembangunan bandara Tempuling ini dapat turut serta menjadi daya tarik untuk memperluas pembangunan sampai ke hilir Kota Kabupaten Inhil.

Berdasarkan UU No 1 Tahun 2009 Tentang Penerbangan pada Bab 1 Ketentuan Umum Pasal 1 poin 31 Kebandarudaraan adalah segala sesuatu yang berkaitan dengan penyelenggaraan bandar udara dan kegiatan lainnya dalam melaksanakan fungsi keselamatan, keamanan, kelancaran, dan ketertiban arus lalu lintas pesawat udara, penumpang, kargo dan/atau pos, tempat perpindahan intra dan/atau antarmoda serta meningkatkan pertumbuhan ekonomi nasional dan daerah.

Penyelenggaran adalah suatu proses penemuan, pengelompokan dan pengaturan berbagai macammacam aktivitas yang diperlukan untuk mencapai tujuan, menentapkan orang-orang pada setiap aktivis, menyediakan alat-alat yang diperlukan, menetapkan wewenang yang secara relatif di delegasikan kepada setiap individu yang akan melakukan aktivitas-aktivitas tersebut.

Agar penyelenggaraan dapat selalu beradaptasi dengan perubahan lingkungan sekitarnya maka perlu adanya bentuk-bentuk penyelenggaraan sebagai berikut :

a. Struktur organisasi sebagai hubungan internal yang berkaitan dengan fungsi yang menjalankan aktivitas organisasi

b. Kebijakn pengelolaan, berupa visi dan misi organisasi

c. Sumber daya manusia yang berhubungan dengan kualitas karyawan untuk bekerja dan bekarya secara optimal

d. Sistem informasi manajemen yang berhubungan dengan pengelolaan data base untuk digubakan dalam mempertinggi kinerja organisasi

e. Sarana dan prasana yang dimilikim yang berhubungan dengan penggunaan teknologi bagi penyelenggaraan organisasi pada setiap aktivitas organisasi.

Agara penyelenggaran dalam kebandarudaraan untuk menjalankan fungsinya maka dibutuhkan suatu tatanan yang mengatur kebandarudaraan yang mana telah dituangkan pada UU No 1 Tahun 2009 Tentang Penerbangan pada bab XI Kebandarudaraan Bagian Kedua Tatanan Kebandarudaraan Nasional Pasal 193 yaitu :

1. Tatanan kebandarudaraan nasional diwujudkan dalam rangka penyelenggaraan bandar udara yang andal, terpadu, efesien, serta mempunyai daya saing global untuk menunjang pembangunan nasional dan daerah yang ber-wawasan nusantara.

2. Tatanan kebandarudaraan nasional sebagaimana dimaksud pada ayat (1) merupakan sistem perencanan kebandarudaraan nasional yang menggambarkan interdepedensi, interrelasi, dan sinergi antar-unsur yang meliputi sumber daya alam, sumber daya masnusia, geografis, potensi ekonomi, dan pertahanan keamanan dalam rangka mencapai tujuan nasional.

3. Tatanaan kebandarudaraan nasional sebagaimana dimaksud pada ayat (1) memuat :

a. Peran, fungsi, peggunaan, hirarki, dan klasifikasi bandar udara:serta

b. Rencana induk nasional bandar udara

Dari ketiga dasar tatanan kebandarudaraan pada Bandar Udara. Tempuling di Kabupaten Indargiri Hilir merupakan Bandar Udara yang melayani jasa transportasi udara. Serta bandar udra tempuling harus di evaluasi untuk lebih meningkatkan dan dapat menjadi masukan terhadap pendapatan daerah. 


\section{METODE}

Jenis penelitian yang dipilih adalah penelitian kualitatif dengan pendekatan studi kasus yang bersifat deskriftif, yaitu prosedur pemecahan masalah yang diteliti dengan menggunakan cara menjelasakan data yang telah diperoleh dari perpustakaan dan pengamatan lapangan, lalu di analisa dan ditarik sebuah kesimpulan. Adapun lokasi pada penelitian ini adalah di Kabupaten Indragiri Hilir Dinas Perhubungan Dan Komunikasi Informatika. Penelitian ini menetapkan informan sebagai sumber informasi untuk mendapatkan informasi data yang dibutuhkan dalam penelitian ini dengan menggunakan teknik purposive sampling. Adapun informan dalam penelitian ini ialah (1) informan kunci yaitu Kepala dinas perhubungan Komunikasi Dan Informatika, kabupaten indragiri hilir, (2) kepala bidang Badan Lalu Lintas Dinas Perhubungan Komunikasi Dan Informatika, (3) penumpang bandr udra tempuling sebagai informan pelengkap yaitu orang yang mengetahui masalah dalam penelitian. Walaupun individu tersebut tidak terlibat langsung, adapun informan tersebut adalah penumpang bandar udara tempuling.

Teknik yang dilakukan dalam pengumpulan data yaitu melalui : (1) wawancara adalah proses tanya jawab dalam penelitian yang berlangsung secara lisan dimana dua orang atau lebih bertatap muka mendengar secara langsung informasi-informasi atau keterangan-keterangan. Wawancara dilakukan untuk mengali data secara mendalam tentang pertanyaan-pertanyaan yang ada dalam fokus penelitian. Pengumpulan data dengan dilakukan tany jawab saecar langsung kepa informan terpilih baik (pejabat struktural) dan inforam diluar pejabat struktural yang berkaitan dengan tujuan penelitian. (2) Observasi merupakan pengumpulan data dengan cara melihat dengan dekat keadaan objek peneliti atau mengamati langsung terhadap objek yang diteliti.(3) dokumentasi yaitu mencari data mengenai hal-hal atau variabel yang berupa catatan, transkip, buku, surat kabar, majalah,arsip, notulen rapat, agenda dan sebagainya. Pada penelitian ini dokumentasi digunakan untuk mempelajari sumber dokumentasi terutama yang ada pada bandara Tempuling.

\section{HASIL DAN PEMBAHASAN}

Bandar Udara tempuling perlu untuk dilakukan sebuah evaluasi, mengingat kebijakan yang telah direncanakan belum bisa diimplementasikan dengan baik. Hal ini sangat disayangkan mengingat sudah 14 tahun kebijakan ini diterbitkan. Melihat tidak sejalannya antara evaluasi kebijakan dengan menggunakan teori tipe evaluasi menurut Nurcholis dengan hasil sebagai berikut:

\subsection{Input}

Input adalah masukan yang dipergunakan untuk pelaksanaan suatu kebijakan.

a. Sumber daya manusia berperan besar bagi kesuksesan suatu organisasi, banyak organisasi menyadari bahwa unsur manusia dalam suatu organisasi dapat memberikan keunggulan bersaing, mereka membuat sebuah sasaran, strategi, inovasi, serta tujuan dari kebijakan dapat tercapai

Berdasarkan observasi yang penulis lakukan di lapangan, sumberdaya manusia dari kebijakan Kebandarudaraan pada Bandar Udara Tempuling Di Kabupaten Indragiri Hilir belum tercapai. Hal dapat kita bahwa tujuan dari kebijakan ini. dari semua rencana yang telah ditetapkan belum tercapai secara keseluruhannya kondisi dilapangan. Didukung oleh hasil wawancara dengan Kepala Dinas Perhubungan yaitu sebagai berikut :

"Pada dasarnya sumber daya manusia yang dibutuhkan dalam sebuah organisasi seperti pemerintahan, khususnya di dinas perhubungan namun pada kenyataannya kita tidak miliki cukup sumber daya manusia untuk menangani masalah bandar udara tempuling akan tetapi, dinas perhubungan kabuapetn indragiri 
hilir memang sampai saat ini masih memerlukan bantuan dari pihak lain yaitu pihak japura dalam proses penerbangan".

Sejalan hasil wawancara dengan kepala dinas perhubunga tersebut, kepala bidan lalu lintas menegaskan bahwa :

"Sumber daya manusia untuk dinas perhubungan cukup baik, namun jika untuk bandr udara tempuling masih jauh dari maksimalnya sumber daya manusia yang dibutuhkan, karena saat waktu ini pun kita masih kekurangan sumber daya manusia, dan kita juga meminta bantuan dari pihak penerbangan japura untuk membantu kita dalam proses pemberangkatan. Itu biasanya pas ada pemberangkatan pihak kita akan menghubungi mereka."

b. Sarana dan prasana, mengenai sarana dan prasana yang ada di bandar udara tempuling, maka penulis menanyakan kepada kepala dinas perhubungan mengenai sarana yang ada di sana?

"Untuk masalah sarana dan prasana berupa fasilitas bandar udara tempuling susah sesuai dengan keputusan menteri perhubungan no 39 tahun 2019 dimana seluruh fasilitas dalam kebutuhan penerbangan kita ada, namun kondisi saat ini di lapangan sebagian besar mengalami kerusakan ringan sampai berat akibat tidak terpelihara dengan baik".

Sedangkan wawancara penulis dengan bapak Ryanto Musri sebagai berikut :

"Kalau untuk fasilitas sarana dan prasana bandar udara tempuling memang sudah hampir seluruhnya fasilitas itu rusak, apalagi bandar udara tempuling sekarang kondisinya dalam tahap penghibahan kepusat, dan pemda sendiri tidak bisa mengeluarkan pembiayaan untuk melakukan perawatan terkait dengan UU no 23 tahun 2014 tentang pemda, sehingga kalau kita lihat di lokasi bandar udara tempuling memang sangat terbengkalai itulah salah satunya kenapa bandara tempuling ini tidak berjalan ataupun beroperasi seperti biasanya".

Dari hasil wawancara dia atas maka penulis dapat menarik kesimpulan bahwa masukan dalam kebijakan berupa sumber daya manusia dan sarana dan prasana bandr udara tempuling masih belum maksimal. Hal ini tentu akan mengakibatkan hambatan dari penyelenggaraan bandar udara sendiri, apalagi terkait dengan UU no 23 tahun 2014 tentang pemerintah daerah.

\subsection{Proses}

Proses adalah serangkaian tahap kegiatan mulai dari menentukan sasaran sampai tercapainya tujuan.

a. Sasaran maksudnya kebijakan yang di tuangkan dengan sasaran sebagai cara untuk memberikan arahan pada kebijakan dapat berjalan dengan fungsinya sehingga sasaran kebijakan tersebut dapat tertuju dengan tepat.

Untuk melihat sasaran kebijakan bandra udara tempuling maka penulis mewawancarai kepala dinas perhubungan sebagai berikut:

"Yang jelas, semua kebijakan pastinya diharapkan untuk kepentingan besama ya. Untuk membangun bandar udara tempuling sendiri tentunya pihak pemerintah telah mengkaji dan menganalisa terlebih dahulu dimana harusnya bandar udara tempuling ini dibangun, kelebihan dan kelamahannya, melihat pertumbuhan ekonomi di daerah tersebut, faktor lingkungan, juga melihat aspek keselamatan dan keamanan. Saya rasa semua hal tersebut sudah dikaji dengan baik oleh pemerintah daerah, cuman sekarang implementasinya saja yang belum maksimal".

Sedangkan menurut kepala bdan lalu lintas bidang perhubungan udara menjelasakan bahwa :

"Untuk kebijakan bandar udara tempuling sendiri sudah terpenuhi, walaupun memang masih banyaknya kekurangan sehingga sasaran yang telah direncanakan tidak tepat dan hal ini juga terkendala pada UU no 23 tahun 2014 tentang pemda".

Berkaiatan mengenai proses kebijakan yang di keluarkan, untuk melihat keefesiensian pelaksanaan. 
b. Efesiensi

Efisiensi adalah sebuah cara untuk mencapai suatu tujuan dengan berbagai cara agar tujuan tersebut dapat terlaksana. Dimana didalam efisiensi dari sebuah kebijakan melihat berapa sumber daya yang digunakan untuk penerapan sebuah kebijakan. Kebijakan yang telah diimplementasikan pemerintah untuk mengetahui seberapa banyak usaha yang diperlukan untuk mencapai hasil yang diinginkan. Jika dilihat dari $\mathrm{sdm}$, biaya, saran prasana dan teknologi yang telah maksimal diberikan dalam penerapan kebijakan bandar udara tempuling, tetapi tingkat efektivitas kebijakan tersebut rendah, maka dapat dikatakan bahwa kebijakan tersebut belum efisien.

Dari wawancara penulis dengan kepala dinas perhubungan sebagai berikut :

"Saya rasa dan percaya bahwa semua aspek sudah melakukan hal terbaik. Setiap tahun kita telah melakukan evaluasi bersama. Ya meskipun sebenarnya bandar udara ini menjadi tanggungjawab Pemerintah Daerah, dan kita sebagai dinas yang terkait tentunya telah melakukan banyak upaya-upaya agar bandar udara tempuling dapat mencapai tujuan dari kebijakan yang telah di keluarkan selama 14 tahun terakhir ini.

Selanjutnya menurut kepala badan lalu lintas :

"Kalau untuk melihat keefesiensian dari bandar udara tempuling dalam peroses pelaksaaannya, saya rasa belum seefesein bandar udara yang ada diseluruh indonesia, namun dengan keterbatasan yang kita meiliki kita (dishub) selalu berupaya agar kebijakan yang di telah ada berkesinambungan terhadap pelaksaannya, walaupun memang pada kenyataannya masih banyak kelemahan sana sini yang kita alami, terutama dalam sumber daya manusia, dan biaya. Alagi dalam proses yang seperti ini kita tentunya tidak bisa melakukan anggaran pengeluaran terhadap bandar udara tempuling"

Jadi dari dua indikator penilaian diatas kebijakan yang telah ditranspormasikan dalam sentuk pelayanan langsung pada masyarakat pengguna jawa transportsi udara sasarannya sudah tepat akan tetpi belum terefesiensi dengan implementasi, apalagi sejak dadanya peraturan UU no 23 tahun 2014 tentang pemerintah daerah.

\subsection{Output}

Output yaitu hasil dari pelaksanaan kebijakan apakah suatu pelaksana kebijakan menghasilkan produk sesuai dengan tujuan yang telah ditetapkan.untuk melihat hasil dari kebijakan tersebut maka penulis mewawancarai Kepala Dinas Perhubungan.

"Pegawai kita sudah melakukan tugas dengan sangat baik ya, untuk melakukan inovasi-inovasi agar bertambahnya masyarakat yang menggunakan jasa transportasi ini, dan kita juga telah melakukan yang terbaik dari segi pelayanan agar semakin meningkatnya jumlah penumpang, serta evaluasi yang kita lakukan tepat pada sasaran yaitu berupa msyarakat".

Adapun menurut pak Ryanto Musri selaku kepala badan lalu lintas

"Sebenarnya kebijakan yang dikeluarkan bersama ini melibatkan banyak pihak bukan hanya pemda saja, namun memang terlihat pemda yang bertanggung jawab untuk mengimplementasikan agar bandar udara tempuling ini memenuhi sasaran yang ada dalam pelaksanaannya, dan saya rasa sasarannya sudah tertuju dengan benar, buktinya masyarakat kita banyak juga yang menggunakan pelayanan bandar udara ini ya, walaupun memang tidak semua masyarakat menggunakan pesawat untuk berpergian ke Provinsi.

Pernyataan diatas juga didukung dengan jumlah penumpang setiap tahunnya menggunakan bandar udara Tempuling Kabupaten Indargiri Hilir sebagai berikut: 
Tabel 5.1.3 Jumlah Penumpang Datang Dan Pergi Di Bandar Bandar Udra Tempuling Di Kabupaten Indragiri Hilir

\begin{tabular}{|l|l|l|l|}
\hline No & Tahun & Penumpang datang & Penumpang pergi \\
\hline 1 & 2016 & 271 & 314 \\
\hline 2 & 2017 & 151 & 291 \\
\hline 3 & 2018 & 329 & 416 \\
\hline 4 & 2019 & 191 & 337 \\
\hline \multicolumn{2}{|l}{ Jumlah } & 942 & 1358 \\
\hline
\end{tabular}

Sumber : Dinas Perhubungan Kabupaten Indragiri Hilir

Dapat dilihat bahwa pelaksaan kebijakan mengenai bandar udara tempuling sebenarnya sudah terpenuhi namun memang tidak semua pelaksaannya tertuju dengan baik, namun dilihat dari jumalah penumpang setiap tahunnya mengalami kenaikan dan penurunan ini menggambarkan bahwa sebenarnya masyarakat Kabupaten Indragiri Hilir ini sudah mengetahui tentang kebijakan bandar udara Tempuling.

\subsection{Outcomes}

Outcomes adalah suatu kebijakan yang berdampak nyata bagi kelompok sasaran dengan tujuan yang telah ditetapkan. Berdasarkan observasi yang dilakukan peneliti dilapangan outcomes terhadap pemanfaat dari kebijakan Tatanan Kebandarudaraan pada bandar udara Tempuling masih belum terlihat kontribusnya kepada ketiga kelompok kebijakan yaitu pemerintah, swasata, dan masyarakat.

Untuk menunjang hasil yang masksimal dalam penelitian ini maka peneliti melakukan wawancar kepada beberapa pihak terkait mengenai dampak yang di hasilkan dalam kebijakan tersebut.

Berdasarkan hsil wawancara dengan bapak Ryanto Musri selaku kepala badan lalu lintas sebagai berikut:

"Ya tanggungjawab itu sebenarnya banyak ya, stekholder yang terlibat didalamnya. Pemerintah sebagari legilatornya, kemudian masyarakat sebagai user dan kemudian sebagai inspektor ada Otoritas Bandara. Outcomes adalah berkenaa dengan pelaksaan kebijakan yang berdampak nyatan terhadap kelompok sasaran dari suatu kebijakan tersebut. dalam hal target kita setiap tahunnya juga mempatokan jumlah penumpang yang datang dan pergi walaupun kadang yaa... kadang lebih, kadang kurang dari jumlah yang kita targetkan". untuk mempekuat hasil wawancara dengan dinas terkait maka penulis melihat juga dari aspek penumpang terkait dampak kebijakan terhadap masyarakat yaitu:

"Dilihat dari keseluruhan bandara tempuling itu sudah cukup bagus, dalam segi perencaan untuk kemajuan Daerah Indragiri Hilir sendiri, apalagi biaya pembangunannya cukup besar yang dilontarkan, saya sendiri dapat merasakan dampak nyata dari kebijakan tersebut ya, dulu kalau mau ke pekanbaru itu pakai travel memerlukan 7 sampai 8 jam perjalanan untuk duduk di mobil, tapi dengan adanya bandar udara tempuling ini memudahkan saya dan mengefesienkan waktu yang tadinya lama dapat dimanfaatkan untuk kepentingan lain, dan ini juga layak untuk dicoba bagi masyarakat inhil yang memang memiliki kepentingan-kepentingan mendesak".

\section{KESIMPULAN}

Setelah peneliti mengelompokkan, membandingkan, mengolah dan membahas hasil penelitian mengenai evaluasi kebijakan Kebandarudaraan pada Bndar Udara Tempuling di Kabupaten Indragiri Hilit maka peneliti dapat menarik sebuah kesimpulan yaitu:

Dinas Perhubungan Kabupaten Indargiri Hilir memiliki fungsi yang sangat penting dalam menangani bidang transportasi secara keseluruhan. Sehubungan dengan mengevaluasi bandar udara 
tempuling yang telah dilaksanakan selama ini. Hasil yang di temukan dalam penelitian ini berdasarkan indikator input, proses, output, dan outcomes dalam kebijakan bandar udara tempuling. Dimana kebijakan dapat dikatakan berhasil apabila kebijakan tersebut tepat sasaran dan tujuan yang ditetapkan, sehingga kebijakan tersebut dapat dikatakan efisiensi bila terdapat perbandingan mengarah pada perbaikan dan manfaat yang berdampak signifikan terhadap daerah, dan masyarakat. Maka, dapat disimpulkan bahwa didalam pelaksanaan kebijakan Kebandarudaraan pada bandar udara tempuling di kabupaten indragiri hilir belum maksimal untuk penetapannya.

\section{SARAN}

Faktor penghambat penyelenggaraan bandar udara tempuling ini meliputi: keterbatasan Sumber Daya Manusia (SDM) baik dalam segi kualitas maupun kuantitas dalam perencanaan hingga dalam pelaksanaan, selain itu keterbatasan kewenangan Pemerintah daerah Kabupaten Indragiri Hilir dalam menangani kegiatan bandar udara. Tidak berkesinambuanganya pemerintah daerah dalam melihat aspek jangka panjang terhadap bandar udara, Serta kurangnya sosialisasi dari pemerintah kepada masyarakat mengenai bandar udara tempuling. Oleh sebab itu perlunya peningkatan sumber daya manusia pemerintah daerah kabupaten Indragiri hilir dalam upaya perbaikan perencanaan dan pelaksanaan terhadap kebijakan Bandar udara tempuling.

\section{DAFTAR PUSTAKA}

[1]. Undang-Undang No 1 Tahun 2009 Tentang Penerbangan Kebandaraudaraan

[2]. Keputusan Menteri Perhubungan No 39 Tahun 2019 Tentang Tatanan Bandarudaraan Nasional

[3]. Peraturan Menteri Perhubungan No 9 Tahun 2016 Tentang Kriteria Dan Penyelenggaraan Kegiatan Angkutan Udara Perintis

[4]. Anggara, Sahya, 2012, Ilmu Administrasi Negara, Graha Pustaka, Jakarta

[5]. Agustino ,Leo, 2016, Dasar-Dasar Kebijakan Publik Edisi Revisi, Alfabeta, Jakarta

[6]. B.Aji, Firman, 1990, Perencanaan Dan Evaluasi, Bumi Aksara, Jakarta

[7]. Budi,Winarno, 2007, Kebijakan Publik Teori Dan Proses, Media Perssindo, Yogyakarta

[8]. Dunn, William N. 2003. Pengantar Analisis Kebijakan Publik (edisi kedua). Yogyakarta: Gadjah Mada University Press

[9]. Damin, Sudarwa, 2000, Pengantar Studi Penelitian Kebijakan, Edisi Pertama, Cetakan Pertama, Bumi Aksara, Jakarta

[10]. Hamdi, Muchlis, 2015, Kebijakan Publik: Proses, Analisis, Partisipasi, Ghalia Indonesia, Bogor 
[11]. Hariyanto, Eri, 2017, evaluasi Kebijakan, Sukuk Negara Sebagai Instrumen Pembiayaan APBN, Gava Media, Yogyakarta

[12]. Islamy, Irfan. 1994. Kebijakan Publik. Jakarta: Proyek Pelita

[13]. Irawan, Prasetya, 2006, Penelitian Kualitatif Dan Kuantitatif Untuk Ilmu-Ilmu Sosial, UI, Jakarta

[14]. Johanes, Caharles O. 1997, An Introduction To The Study Of Public Polic : Edisi ke 2. Duxbury Press, Masschusettes

[15]. Nurdin, Usman, 2002, Konteks Implementasi Berbasis Kurikulum, PT Raja Grafindo Persada, Jakarta

[16]. Nurcholis, Hanif dkk, 2009, Perencanaan Partisifatif Pemda,PT Grasindo, Jakarta

[17]. Nugroho, Riant. 2003. Kebijakan Publik Formulasi, Implementasi dan Evaluasi. Jakarta: Elex Media Komputindo

[18]. Roro, Mas Lilik Ekowati, 2015, Perencanaan Implementasi Dan Evaluasi Kebijakan Atau Program, Pustaka Cakra Surakarta, Surakarta

[19]. Samodra, Wibawa dkk,1994. Evaluasi Kebijakan Publik. PT. Raja Grafindo, Jakarta

[20]. Supriyanto, Budi. 2009. Manajemen Tata Ruang. Tangerang: Media Brilian

[21]. Subarsono, 2010. Analisis Kebijakan Publik : Konsep, Teori, Dan Aplikasi, Pustaka Pelajar, Yogyakarta

[22]. Wirawan, 2016, Evaluasi : Teori, Model, Metodologi, Standar, Aplikasi Dan Profesi, PT. Raja Grafindo Persada, Jakarta

[23]. Widodo, Joko, 2018, Analisis Kebijakan Publik : Konsep Dan Aplikasi Proses Kebijakan Publik,Media Nusa Creative, malang

[24]. Zainal, Said Abidin, 2012, Kebijakan Publik, Salemba Humanika, JakartaKeputusan Menteri Perhubungan No 39 Tahun 2019 Tentang Tatanan Bandarudaraan Nasional 